\title{
Educación inclusiva y democracia
}

\author{
Inclusive education and democracy ${ }^{1}$
}

\author{
Alfredo Gaete \\ Centro de Desarrollo Local, Educación e Interculturalidad (CEDEL) \\ Pontificia Universidad Católica de Chile, Campus Villarrica \\ Laura Luna \\ Centro de Estudios Interculturales e Indigenas (CIIR) \\ Centro de Justicia Educacional (CJE) \\ Centro de Desarrollo Local, Educación e Interculturalidad (CEDEL) \\ Pontificia Universidad Católica de Chile, Campus Villarrica
}

Recibido: 12/09/2019

Aceptado: 27/11/2019

\begin{abstract}
In this article it is argued that inclusive education can be construed as a response to the crisis of modern democracy and its school project. Such a response consists, in part, in the production of a new school normativity, in the light of the ideals of participative democracy. The argument tackles the origins of schooling after the democratic revolutions that took place during the 18th and 19th centuries, presents the main features of participative democracy, and shows the connections between the latter and the inclusive project in education. These considerations are expected to clarify the concept of inclusive education, given the current lack of agreement about it.

KEY WORDS: participative democracy; social inequality; civic education; inclusive education; social exclusion; educational history; equal opportunity; social justice.

\section{RESUMEN}

En este artículo se argumenta que la educación inclusiva puede entenderse como una respuesta a la crisis de la democracia moderna y su proyecto escolar. Dicha respuesta consiste, en parte, en la producción de una nueva normatividad escolar, alumbrada por los ideales de la democracia participativa. En el transcurso del argumento se aborda el origen político de la escuela tras las revoluciones democráticas de los siglos XVIII y XIX y se presentan las características principales de la democracia participativa, así como su conexión con el proyecto inclusivo en educación. Se espera además que estas consideraciones sirvan para clarificar el concepto mismo de educación inclusiva, sobre el cual hay bastante desacuerdo en la actualidad.
\end{abstract}

PALABRAS CLAVE: democracia participativa; desigualdad social; educación ciudadana; educación inclusiva; exclusión social; historia de la educación; igualdad de oportunidades; justicia social.

1 Estamos en deuda con Manuela Álamos por todas las conversaciones que tuvimos con ella sobre varios puntos de este trabajo y que fueron muy importantes para el resultado final.

Autor de correspondencia

Alfredo Gaete, Director Académico del Campus Villarrica de la Pontificia Universidad Católica de Chile. E-mail agaetes@uc.cl. ORCID: http://orcid.org/0000-0002-1274-5638. 


\section{Introducción}

El concepto de inclusión aparece cada vez con más fuerza en el debate educacional contemporáneo. Sin embargo, y tal como ha puntualizado recientemente Slee (2018), estamos lejos de contar con una teoría general de la educación inclusiva, sobre todo porque el concepto se usa habitualmente para referir propuestas educacionales radicalmente diferentes, incluso contrapuestas (véase también Ainscow y Miles, 2008; Artiles, Kozleski, Dorn y Christensen, 2006; Florian, 2008; Göransson y Nilholm, 2014; Graham y Slee, 2008; Hodkinson, 2005; Infante, 2010; Nilholm, 2006; Woodcock y Hardy, 2017).

Una de las tensiones conceptuales más importantes es la que se da entre dos tipos de propuestas, que podemos caracterizar como "integracionistas" y "revisionistas". Las primeras conciben la inclusión como un enfoque orientado a posibilitar que las y los estudiantes con "necesidades educativas especiales" se adapten efectivamente a los requerimientos de la escolaridad. En este marco, la educación inclusiva se presenta como una versión mejorada de la educación especial, motivada por la convicción de que todas las personas pueden y tienen derecho a ser educadas en los centros educativos "regulares", siempre y cuando estos cuenten con programas de asistencia especializada para quienes lo requieran (véase, por ejemplo, Agbenyega y Klibthong, 2014; Bailey, Nomanbhoy y Tubpun, 2015; Clark, Dyson y Millward, 1995; de Boer, Pijl y Minnaert, 2011; Rafferty, Boettcher y Griffin, 2001; Ruijs y Peetsma, 2009; Turnbull, Turnbull y Leal, 1995). Las propuestas revisionistas, en cambio, entienden la inclusión como un movimiento orientado hacia la transformación de la educación general, a partir de una revisión crítica de las prácticas, políticas y culturas que caracterizan a las instituciones educativas (véase, entre muchos otros, Ainscow, 2011; Booth, 1998; Booth y Ainscow, 2002; Casanova, 2011; de la Puente, 2009; Echeita, 2007; Escribano y Martínez, 2013; Florian, 2008; Graham y Slee, 2008; León, 2012; Lipsky y Gartner, 1996; López, 2013; Parrilla, 2002; Slee, 2001; Stainback y Stainback, 1999; Thomas y Loxley, 2007). Desde esta perspectiva, y en abierto contraste con las propuestas integracionistas, resulta inapropiado categorizar a alguien como teniendo "necesidades educativas especiales". En consecuencia, se cuestiona la pertinencia misma de una educación "especial". Además, las discusiones y acciones en el marco de las propuestas revisionistas suelen trascender ampliamente el ámbito de la diversidad física o cognitiva, abarcando también problemáticas de clase, género, etnia, religión, cultura, justicia social y otras. La educación inclusiva se despliega aquí como un llamado a reconceptualizar críticamente la organización, el funcionamiento y los fines de la educación formal tal como la conocemos hasta ahora; y, en esa medida, aspira no tanto a que los y las estudiantes se adapten a ella sino más bien a que la educación se adapte al estudiantado y a la comunidad en general.

En este trabajo tomamos partido por la concepción revisionista, sin perjuicio de lo cual reconocemos que, históricamente, el surgimiento de la integración fue un paso importante para el surgimiento de la inclusión (Casanova, 2011; León, 2012; Parrilla, 2002). Quizá sea por eso mismo que muchos educadores se inclinan todavía hacia una visión más bien integracionista del concepto, aunque recientemente Slee (2018) ha planteado una tesis más dura. A su juicio, la tendencia a interpretar la educación inclusiva desde el paradigma integracionista obedece a un intento por quitarle a la primera su sello de insurrección. Como sea, el hecho es que existe un severo desacuerdo conceptual respecto de qué es la educación inclusiva; y eso no solo dificulta la construcción de una definición unitaria del concepto, sino que además pone sobre la mesa la pregunta de si vale la pena conservar dicho concepto o si no sería mejor producir una alternativa menos problemática. Nosotros nos inclinamos por lo primero, por razones que expondremos más adelante y que tienen que ver con la motivación política que subyace al proyecto inclusivo (concebido desde la óptica revisionista).

Exponer esa motivación es uno de los propósitos centrales de este ensayo, cuyo argumento nuclear puede resumirse del siguiente modo. La crisis de las democracias modernas dio paso a la búsqueda de una nueva forma de democracia, cuya realización demanda una renovación profunda del proyecto escolar moderno; la educación inclusiva emerge como un intento por llevar a cabo esa renovación, propugnando una normatividad radicalmente distinta a la promovida por la escolaridad moderna. Para desarrollar este argumento tendremos que decir algo sobre el origen de la escuela y 
exponer la forma específica de democracia a la que se aspira desde la inclusión. Esperamos que estas consideraciones - y este es el otro propósito central del ensayo - ayuden a clarificar en algún grado el concepto de educación inclusiva que hay detrás de las propuestas revisionistas.

\section{El fracaso del proyecto político de la escolaridad moderna}

Todas las sociedades humanas se sostienen sobre ideales normativos: creencias, principios y valores que se inculcan desde la infancia temprana y que dan a esos grupos de personas el pegamento cultural que los convierte en sociedades propiamente tales (véase, por ejemplo, Bourdieu, 2000; Dewey, 2012; Dubet, 2004; Durkheim, 1997; Giddens, 1987; Merton, 1964; Peña, 2015; Spindler, 1987). Durante siglos, estos ideales fueron inculcados en las relaciones sociales informales, principalmente al interior de la familia; pero entre los siglos XVIII y XIX aparece en la historia humana la escuela, institución que tomará rápidamente el protagonismo en el proceso de incorporación de las nuevas generaciones al mundo simbólico de la sociedad (Tiramonti, 2005). Spindler (1987) describió esta acción socializadora de la escuela en términos de una transmisión cultural orientada al "reclutamiento" de nuevos miembros de la comunidad "para su ingreso en un sistema cultural y para el ejercicio de roles y status específicos" (p. 237), así como a la "mantención" de dicho sistema mediante "la inculcación de valores, actitudes y creencias específicas" (p. 233). Se trata, desde luego, de una acción impositiva, en la que al menos algunos valores o principios son inculcados de forma irreflexiva. Por eso la escuela tiene y siempre tendrá, inevitablemente, una función en cierto sentido violenta: porque ha sido diseñada para someter a los miembros de una sociedad a la normatividad por la cual esa sociedad se constituye como tal. ${ }^{2}$

Ahora bien, los ideales normativos de la escolaridad moderna fueron instituidos en buena medida con el objeto de dar vida a las nuevas democracias que surgieron con el advenimiento de los Estados-nación, en muchos casos después de un periodo de conflictos bélicos revolucionarios, como la Independencia de los Estados Unidos, la Revolución Francesa o los procesos independentistas en América Latina durante el siglo XIX (véase, por ejemplo, Tiramonti, 2005; Dubet, 2003). En este contexto, la escuela surge como un dispositivo de educación masiva del cual se esperaba, entre otras cosas, que pudiera inculcar principios y valores democráticos fundamentales. Esto ocurrió con tal fuerza y rapidez que, a principios del siglo XIX, la relación entre democracia y educación ya estaba completamente naturalizada (véase, por ejemplo, Dewey, 2012).

Pero el proceso de formación y consolidación de los Estados-nación agregó a la normatividad escolar otros elementos, asociados a la creación y el fortalecimiento de las identidades nacionales. En algunos países esta agenda nacionalista de la educación se declaró explícitamente. Chile nos proporciona un buen ejemplo. A principios del siglo XIX, apenas iniciado el proceso de independencia del Rey de España, el país funda su primera escuela en el contexto de un proyecto educacional que, en palabras de uno de sus ideólogos, tenía por objeto "crear, dar existencia política [...] a una nación que jamás la ha tenido" (Juan Egaña, citado en Serrano, de León y Rengifo, 2012, p. 63; véase también Díaz Arce y Druker, 2007). Un siglo más tarde, la escritora y profesora Gabriela Mistral declaraba, con razón, que "según como sea la escuela, así será la nación entera" (2017, p. 118). ${ }^{3}$

De modo que la escuela se convirtió en el dispositivo principal que los Estados modernos utilizaron para homogeneizar a la población alrededor de identidades nacionales. Hoy, ya bien

\footnotetext{
2 Incluso si lo que se quisiera imponer fuera, irónicamente, la autonomía (Peña, 2015). Esto se relaciona, por supuesto, con la noción de violencia simbólica y la función reproductiva de la escuela (Bourdieu y Passeron, 1981).

3 En otro trabajo (Luna y Gaete, 2019) hemos llevado a cabo un análisis etnográfico de cómo esta herencia histórica opera, en la actualidad, sobre el sistema escolar chileno. Para una reflexión sobre la construcción de la alteridad en el contexto de la acción educativa, véase Skliar y Téllez, 2008; véase también Tiramonti, 2005.
} 
entrados en el siglo XXI, esta función homogeneizante de la escuela ha caído en un profundo descrédito al interior de la academia (Hopenhayn 2006; Chomsky, 2000; Díaz Arce y Druker, 2007; Grignon, 1990; Luna y Gaete, 2019; Terrén, 2003; Tiramonti, 2005). Un segundo foco de críticas se gestó desde la teoría de la reproducción (véase, por ejemplo, Bourdieu y Passeron 1981; Giroux, 1986; Kingston, 1986), a la luz de la cual la escuela reveló ser un dispositivo de perpetuación de la desigualdad social, manteniendo estructuras oligárquicas en las que unas pocas familias se traspasan el poder de una generación a la otra. Chile ofrece, de nuevo, un excelente ejemplo, toda vez que su proyecto escolar se construyó desde el principio sobre la base de la segregación social. ${ }^{4}$ Así, para educar a la "clase gobernante" se funda en 1811 la primera escuela del país, el Instituto Nacional, en el entendido de que la educación tiene una "tarea política, que forma en los pueblos cultos la clase gobernante que ha de reemplazar a las antiguas, derribadas por la revolución i la cultura" (Valentín Letelier, citado en Ruiz, 2012, p. 107; véase también Aedo-Richmond, 2000; Serrano, de León y Rengifo, 2012); mientras que, para educar a los gobernados, se funda unas décadas más tarde la Escuela Normal de Preceptores, a la luz de Sarmiento y su afán por "civilizar" a la población "salvaje" (Serrano, de León y Rengifo, 2012; los términos entrecomillados son del propio Sarmiento). ${ }^{5}$

Teniendo en cuenta estos procesos de homogeneización y desigualdad que la escolaridad favoreció desde sus orígenes, no es de extrañar que las democracias modernas hayan terminado produciendo "individuos similares pero no iguales" (Touraine, 2000, p. 10). Esto constituye, por supuesto, un fracaso del modelo moderno de democracia, sobre todo en lo que respecta a la realización de dos insignes valores de la tradición democrática: la libertad y la igualdad. La homogeneización de la población socavó directamente la libertad democrática fundamental que individuos y culturas tienen de ser únicos (el derecho a la diferencia, si se prefiere), mientras que la desigualdad era precisamente aquello que, supuestamente, las revoluciones democráticas iban a resolver. Para usar las categorías de Fraser (2000; 2008), una democracia debe asegurar, al mismo tiempo, el reconocimiento del otro - con las libertades que esto conlleva - y la redistribución del poder en búsqueda de la equidad social (véase también Cortina, 1993; Dworkin, 2000; López, 2013; Sánchez-Parga, 2005; Subirats, 2005; Taylor, 1997, 2012; Touraine, 1997, 2000; Walzer, 2008). En estos dos ámbitos centrales, el proyecto escolar moderno llevó a la democracia exactamente en la dirección opuesta: en vez de avanzar hacia una valoración de la diversidad en un marco de igualdad de derechos y oportunidades, impulsó una homogeneización inequitativa de la sociedad; y, en esa medida, fracasó tanto como ella, toda vez que favorecer el desarrollo de la democracia en la sociedad era una de la motivaciones principales de dicho proyecto. La educación inclusiva, tal como la concebimos nosotros, es un intento por revertir este fracaso, como mostraremos en breve.

4 Hemos obtenido nuestros dos ejemplos del caso chileno simplemente porque estamos más familiarizados con el devenir de la educación en ese país. Naturalmente, la escolaridad moderna no es un proceso uniforme, sino una historia que cada país ha construido con sus propias particularidades. Aquí hemos intentado describir la tendencia general del proceso, refiriendo elementos que, a nuestro juicio, fueron relevantes en todos los países.

5 La segregación escolar con que se da inicio al proyecto educacional chileno se ha preservado hasta la actualidad (Bellei, 2013; Gaete y Gómez, 2019; Rosas y Santa Cruz, 2013). La primera política que intenta atacarla de manera directa, conocida como la Ley de Inclusión, entró en vigencia recién el año 2016. Por supuesto, esta iniciativa por sí sola no es suficiente para deshacer una estructura de clases que durante dos siglos ha concentrado el poder político y económico en una minoría educada para detentar ese poder por sobre una mayoría educada para obedecer. Un estudio de opinión realizado entre ciudadanos chilenos encontró que estas dos agendas educativas se espejaban en el modo en que las distintas clases sociales conciben la labor de la escuela: a la pregunta de si durante la enseñanza básica se debe fomentar más la disciplina y el orden o, alternativamente, la autonomía y la creatividad, el segmento socioeconómico más alto apuntó mayoritariamente a la autonomía y la creatividad, mientras que el segmento más bajo se inclinó por la disciplina y el orden (Gaete y Ayala, 2015). Aquí hay una clara diferencia sobre qué tipo de ciudadano es el que debe formar la escuela: una diferencia de expectativas cívicas que, creemos, la propia escuela y otras instituciones educativas generaron y mantuvieron a lo largo de los años. 
Por supuesto, es indudable que la modernidad trajo consigo avances en el ámbito de la igualdad y la libertad; piénsese, por ejemplo, en la igualdad de voto y el principio de soberanía popular. Con todo, y tal como apunta Subirats (2005, p. 7), hoy "sabemos muy bien que la igualdad de voto no resuelve ni la desigualdad económica, ni la desigualdad cognitiva, ni la desigualdad de poder y de recursos de todo tipo de unos y otros" (véase también Cortina, 1993; Fraser, 1996; Santos, 2002; Taylor, 1997; Touraine, 2000; Zapata-Barrero, 2001; Zaragoza, 2002). Por otro lado, si bien reconocer el principio de soberanía popular es un paso en el logro de la libertad, en la actualidad existe conciencia creciente de que la libertad sin equidad es una mera ilusión: ningún ciudadano puede declararse políticamente libre si no tiene acceso equitativo a la participación y la toma de decisiones (véase, por ejemplo, Cortina, 1993; Fraser, 2009; Nussbaum, 1999; Pedraza, 2015; Santos, 2002; Subirats, 2005; Taylor, 1997; 2012; Touraine, 1997). La modernidad no logró materializar equitativamente el ideal de la libertad, toda vez que su ímpetu homogeneizante dejó sin reconocimiento a una amplia gama de "minorías": lejos de valorarse, la diversidad fue resistida (y en buena medida desde las escuelas). De modo que la modernidad nos heredó un mundo que, por una parte, "tolera las mayores y peores desigualdades" y, por otra, "no soporta las más mínimas y ligeras diferencias" (Sánchez-Parga, 2005, p. 416).

Ahora bien, este fracaso de la democracia moderna y de su proyecto escolar se cristaliza en uno de los problemas más importantes de las sociedades contemporáneas: la exclusión social. Sea por efecto de la desigualdad, sea por la privación de libertad experienciada por quienes no son reconocidos o abiertamente discriminados, en la actualidad "crece el número de los excluidos, de los sin 'voz"' (Subirats, 2005, p. 8): ciudadanos que no pueden ejercer su derecho a la participación en la misma medida que otros (véase también Castel, 1995; Echeita 2007; Parrilla, 2002; Sánchez-Parga, 2005; Santos, 2002; Tedesco, 2000, 2002; Touraine, 1997; Zaragoza, 2002). Es un fenómeno demasiado familiar como para no advertirlo: clases sociales relegadas a condiciones materiales precarias y acceso a servicios de salud inferiores (a una ciudadanía "de segunda clase", para usar la expresión de Taylor [1997, p. 38]); pueblos originarios cuyas voluntades son apenas consideradas o sencillamente ignoradas en la toma de decisiones políticas; personas que ven sus derechos disminuidos, o que son incluso patologizadas, debido a su orientación sexual, sus características biológicas, su identidad de género, su personalidad o sus particularidades cognitivas; condiciones laborales lamentables, a veces indignas, para mujeres, jóvenes, ancianos, "discapacitados" e inmigrantes, y millones de trabajadores "que sobran en el mundo", como apunta Sánchez-Parga (2005), volviéndose "un estorbo", una "masa de excedentes, de excluidos, de victimables" (p. 418). Esta exclusión de personas y grupos que caracteriza a las sociedades contemporáneas ha sido posibilitada, e incluso favorecida, por la estructura política y económica heredada de las democracias modernas, que no supieron ofrecer alternativas viables para asegurar la igualdad y la libertad de todos los ciudadanos. En ese sentido, y para usar la contundente expresión de Santos (2002), fueron democracias "de baja intensidad", basadas "en la privatización del bien público por élites más o menos limitadas, en la distancia creciente entre representantes y representados y en una inclusión política abstracta hecha de exclusión social" (p. 25).

\section{La democracia participativa}

A fines del siglo XX, la reflexión política comienza a producir propuestas dirigidas a revertir la maquinaria inequitativa y homogeneizante del proyecto político de la modernidad. Basadas en una concepción de ciudadanía diversa e igualitaria (en el plano de las oportunidades y los derechos fundamentales), estas propuestas nos instan a tomar con seriedad los desafíos de la libertad y la igualdad, recuperando además un tercer valor declarado pero en buena medida olvidado por las democracias modernas: el ideal de fraternidad o solidaridad entre las personas. Así describe Touraine este giro del proyecto democrático: 
En nuestra concepción de la democracia combinamos las exigencias complementarias de la libertad y la igualdad, la idea de soberanía popular, que llamamos más gustosos ciudadanía, con la idea de derechos del hombre que inspiró las revoluciones norteamericana y francesa y limita el poder del Estado en nombre de un principio superior a toda realidad social. Esta idea acordó una importancia cada vez más grande al pluralismo, a punto tal que para nosotros el respeto de las minorías cobró tanta significación como el gobierno de las mayorías [...] Libertad, Igualdad, Fraternidad [...] Puesto que la libertad solo tiene sentido porque se reconoce la pluralidad de los intereses, mientras que la igualdad es un principio que se sitúa mucho más allá de las realidades sociales, siempre marcadas por la desigualdad, y la fraternidad, a la que llamamos mejor solidaridad, expresión concreta de la ciudadanía" (Touraine, 1997, pp. 243-245; véase también Taylor, 1997; 2012).

Tras el cambio de siglo, este llamado a la construcción de una democracia solidaria en la que igualdad y libertad puedan florecer juntas se materializa en una nueva ideología política que suele ser descrita como "democracia participativa" (véase, por ejemplo, Canto Sáenz, 2016; Cortina, 1993; Pedraza, 2015; Santos, 2002; Subirats, 2005). Además de propugnar los principios y valores fundamentales de cualquier proyecto democrático (soberanía popular, libertad, igualdad, fraternidad), esta nueva propuesta aspira a "transformar los arreglos institucionales hegemónicos de la democracia representativa" (Pedraza, 2015, p. 75), para lo cual agrega a esos principios y valores tres elementos que aquí referiremos como la "ética de la igualdad diferente", el "pluralismo" y el "principio de participación". Estas tres nociones fundamentales, que explicaremos a continuación, se van a situar en el núcleo ideológico y normativo del proyecto inclusivo en educación.

La ética de la igualdad diferente es un marco axiológico en el cual la valoración por la diferencia convive con, y de hecho se nutre de, una igualdad de base entre todas las personas: si hay algo común a todos los seres humanos, algo que pueda considerarse relativamente universal, es su inclinación a ser diferentes, a construir su propia identidad (Taylor, 1997; Touraine, 2000). Por eso, una ética que valora genuinamente la igualdad debe, al mismo tiempo y en la misma medida, valorar la diferencia (véase también Gimeno Sacristán, 2001). En este sentido, la igualdad promulgada y defendida por este marco axiológico no tiene nada que ver con la homogeneización de los individuos. A lo que apunta es a una igualdad de derechos cívicos o políticos fundamentales entre los ciudadanos, que se traduzca a su vez en una igualdad de oportunidades que evite situaciones de privilegio y exclusión (tan comunes en las democracias modernas) y permita, en definitiva, una participación política no solo universal sino que también equitativa. Desde esta óptica, todas las personas tienen el mismo derecho a participar en la polis, independientemente de sus particularidades individuales o culturales: nadie es "especial" (ni en un sentido de privilegio ni en un sentido peyorativo). La idea es que nuestros derechos fundamentales no provienen de nuestra pertenencia a tal o cual nación (como ocurría en las democracias modernas) ni de ninguna otra condición aparte del mero hecho de ser personas; y uno de los derechos fundamentales derivados de ese hecho es el derecho a ser único e irrepetible, es decir, el derecho a ser diferente. En esa medida, la ética de la igualdad diferente defiende la originalidad de todo individuo y la autonomía de toda cultura, pero sin que ello genere inequidades que destruyan la unidad del colectivo: "vivir la diferencia en la igualdad", nos dice Todorov (2001), instándonos a una diferencia que no degenere en relaciones de superioridad e inferioridad y que nos permita "volver a encontrar el sentido de lo social, sin perder la cualidad de lo individual" (p. 259).

Poner este marco axiológico en un terreno ético implica que las prácticas y políticas que se orienten a la luz del mismo se justifican no solo por asuntos de interés, eficacia o utilidad, sino además, y sobre todo, porque responden a un deber moral. Por eso concordamos con Taylor (1997) en que todo el mundo debería ser reconocido por su ser único; y con Fraser (2000, p. 127) en que "deberíamos enfrentarnos a una nueva tarea intelectual y práctica: la de desarrollar una teoría crítica del reconocimiento, que identifique y propugne únicamente aquellas versiones de la política cultural de la diferencia que puedan combinarse de manera coherente con una política social de la igualdad" (el énfasis es nuestro). En esta línea, en una democracia pensada en virtud de la ética de la igualdad 
diferente se esperaría que coexistieran al menos dos tipos de política, que usando la terminología de Taylor (1997) podríamos describir como la "política de dignidad equitativa" y la "política de la diferencia": "con la política de la dignidad equitativa, se pretende que lo establecido sea universalmente lo mismo, una canasta idéntica de derechos e inmunidades; con la política de la diferencia, se nos pide reconocer la identidad única de cierto individuo o grupo, su ser distinto de cualquier otro" (p. 38).

A nivel de la estructura social, una ética como esta debiese materializarse en sociedades pluralistas. En el sentido en que aquí usamos el concepto, una sociedad es pluralista cuando su institucionalidad posibilita una multiplicidad de formas de vida en el marco de la equidad. Dicho de otro modo, la arquitectura institucional de la sociedad es tal que, para tener plena participación en el destino de la polis, no se requiere pertenecer a una cierta clase o grupo cultural, ni tener ciertas características físicas o psicológicas, etc. Toda particularidad biológica, psicológica, cultural y de cualquier otra índole es perfectamente válida y debe ser posible en la medida que no implique inequidad política (privilegios y exclusión). La felicidad de los ciudadanos no puede condicionarse con restricciones institucionales al florecimiento de la diversidad.

Cabe señalar en este punto que nuestra concepción del pluralismo difiere sustancialmente de ciertas concepciones de corte liberal-utilitarista, que tienden a fundamentar la interacción social en relaciones de competencia o de lucha entre distintos grupos (véase, por ejemplo, Schumpeter, 1942). No negamos, naturalmente, que el conflicto y la adversidad cumplan un rol clave en la vida humana, pero a nuestro juicio ni lo uno ni lo otro es - ni tiene por qué ser - la base inescapable de la interacción social (ni menos el desafío principal de la democracia). Más bien por el contrario, nos parece que una sociedad sustentable requiere de un sustrato básico de colaboración, complementariedad y cariño. El pluralismo que aquí promulgamos recupera el ideal democrático de solidaridad, al suponer y promover una conexión amorosa entre los seres humanos (sin perjuicio de que sobre este sustrato solidario puedan e incluso deban darse, en ciertos momentos y para ciertos fines, interacciones conflictivas y juegos de ganar y perder). Esa conexión es, creemos, no solo posible sino además necesaria para alcanzar una comunicación genuina entre las personas y, por lo mismo, para la construcción de sociedades genuinamente democráticas (véase, por ejemplo, Touraine, 1997).

Nótese además que el pluralismo (en el sentido que aquí damos al término) implica un reconocimiento institucional no solo de las diferencias individuales, sino también entre colectivos y mundos de significado. En abierto contraste con las sociedades modernas, cuya cohesión pasaba fundamentalmente por homogeneizar a la ciudadanía alrededor de una única identidad nacional, en una sociedad pluralista se permite la coexistencia (equitativa) de distintas identidades nacionales y, en general, de cualquier otra forma de producción cultural. Por eso nos parece que este tipo de pluralismo se asemeja al "pluralismo cultural" de los debates sobre multiculturalismo y ciudadanía acaecidos en los noventa en algunos países: ante la pregunta respecto de hasta qué punto es posible dar cabida a las diferencias culturales en una sociedad que se rige por principios democráticos, varios filósofos (entre otros Kymlicka, 1995; Parekh, 1995; Taylor, 1997; Touraine, 1997) argumentaron que no hay contradicción alguna entre la aceptación de diferentes manifestaciones culturales y la preservación de una democracia basada en la libertad y la igualdad; y que, por lo demás, el reconocimiento de los derechos culturales es un derivado de los derechos individuales. En este contexto, Kymlicka (1995) propone la noción de "ciudadanía multicultural", apuntando que la libertad individual solo puede ser ejercida cuando hay una variedad de "culturas societales" que proveen a los ciudadanos de un abanico de opciones desde las cuales ellos puedan construir su identidad; que es, precisamente, lo que una sociedad pluralista debe posibilitar a través de sus instituciones fundamentales. Por eso nos resulta especialmente interesante la propuesta de Parekh (2001) de repensar la sociedad británica, que argumenta en favor de la necesidad de dejar de hablar de "nación" y de empezar a hablar de una "comunidad de comunidades e individuos" (p. 695).

Además de una ética de la igualdad diferente y de una estructura social pluralista, la democracia participativa supone la existencia de una ciudadanía activa, realmente comprometida con la acción política. A esto nos referimos con el principio de participación: a la idea general de que la ciudadanía tiene no solo el derecho sino también el deber de involucrarse de hecho en el devenir de su polis. El 
pluralismo ofrece las condiciones institucionales para ello, pero eso no basta; en una democracia participativa, los individuos saben participar (tienen las competencias requeridas para hacerlo) y en efecto lo hacen.

El llamado a la participación ciudadana universal efectiva se opone claramente a la apatía política recomendada aquella visión liberal-utilitarista de la democracia, según la cual es indeseable que el pueblo se involucre demasiado en los asuntos políticos (véase, por ejemplo, Schumpeter, 1942); visión que, tal como apunta Touraine (2000), conduce rápidamente al despotismo ilustrado. Lejos de ese adormecimiento político de las sociedades, el principio de participación nos invita a concebir el involucramiento político de los ciudadanos como un requerimiento democrático inescapable. En consecuencia, el Estado debe no solo proteger dicho involucramiento, sino además promoverlo (Canto Sáenz, 2016; Santos, 2002). Como dice Zaragoza (2002), "no puede haber democracia si no hay demócratas; sin una ciudadanía consciente y activa, tampoco" (p. 17; véase también ZapataBarrero, 2001).

Desde luego que la acción política propugnada por el principio de participación va mucho más allá del mero ejercicio del derecho a voto al momento de elegir representantes; en parte porque ningún sistema de representación logrará jamás dar cuenta de la enorme y cambiante diversidad humana, y en parte porque si mi única acción política es la de delegar poder en otros, en la práctica estoy renunciando al ejercicio de mi libertad. La participación ciudadana debe ser permanente, y no puede reducirse a unos pocos actos formales predeterminados, sino que debe expresarse de distintas maneras y con cierto grado de creatividad y espontaneidad. Tal como apunta Zapata-Barrero (2001), "el ciudadano debe tener constantemente abierta la posibilidad de poder participar en la determinación de los destinos y de los riesgos de su comunidad, de ser activo y creativo, y no un mero recipiente de derechos y de bienes distribuidos" (p. 190).

En resumen, la democracia participativa recoge, junto al ideario democrático tradicional, tres elementos adicionales que, se espera, darán al proyecto democrático los aires de renovación que este necesita tras el fracaso de la modernidad: la ética de la igualdad diferente, que nos brinda un nuevo marco axiológico desde el cual pensar la vida política; el pluralismo, que describe el tipo de estructura social que se requiere para hacer posible la alianza armónica entre libertad, igualdad y solidaridad; y, por último, el principio de participación, según el cual los ciudadanos deben comprometerse efectivamente con una acción política constante y creativa (a través de vías no completamente predeterminadas). Es este escenario político el que entrega a la educación inclusiva su motivación central y su horizonte normativo.

\section{La educación inclusiva: el camino hacia la democracia participativa}

Hemos señalado ya que con el fracaso de la democracia moderna fracasa también el proyecto escolar con el cual se intentó inculcar en la población la normatividad propia de ese programa político. De modo que la escuela, tal como la conocemos hasta ahora, comienza a perder legitimidad y sentido. En esto concordamos con García-Huidobro (2001, p. 217): "la estructura de la escuela viene de un mundo que ya no existe" (véase también Peña, 2015; Tiramonti, 2005). La educación inclusiva, o al menos la versión de esta que aquí presentamos, busca instituir una nueva escuela, que sea capaz de responder a los desafíos de renovación política de la democracia participativa.

Podemos decir, en este sentido, que si la escolaridad moderna surge como un dispositivo de los Estados para llevar a cabo el proyecto democrático nacionalista de la modernidad, la educación inclusiva puede caracterizarse como un dispositivo para hacer realidad los ideales de la democracia participativa. La primera condujo a procesos de homogeneización y estructuras inequitativas reproductoras de privilegios políticos y exclusión; la segunda aspira al florecimiento de la diversidad humana y la participación universal equitativa. En palabras de Escribano y Martínez (2013, p. 19), "la inclusión es una respuesta [...] a la diversidad humana como algo enriquecedor y positivo, desde el marco de los derechos de las personas según el principio de igualdad de oportunidades" (véase además, entre muchos otros, Aguerrondo, 2008; Ainscow, 2011; Casanova, 2011; de la Puente, 2009; 
Escribano y Martínez, 2013; Escudero y Martínez, 2011; Florian, 2008; Gerschel 2003; Lipsky y Gartner, 1996; León, 2012; López, 2013; Parrilla, 2002; Thomas y Loxley, 2007; Thomazet, 2009; UNESCO, 2004). En este sentido tiene razón López (2013) cuando afirma que "en el mundo de la educación hablar de inclusión es hablar de justicia” (p. 262).

En su búsqueda democrática de libertad con equidad, de reconocimiento y redistribución, de diferencia e igualdad, una escuela inclusiva debe defender dos grandes derechos humanos fundamentales: el derecho a ser uno mismo y el derecho a la participación equitativa universal. Estos dos derechos combinados pueden expresarse en el derecho inalienable a que el acceso a la educación no exija la pérdida de la propia identidad: el derecho que todos tenemos a una educación que no sea alienante. ${ }^{6}$ La modernidad nos acostumbró a escuelas que obligaban a los estudiantes a vestirse de cierta forma, a hablar de cierta forma, a moverse de cierta forma; desde la óptica inclusiva, las particularidades individuales o culturales de una persona jamás pueden ser impedimentos para su proceso educativo. Por eso es en principio completamente impropio de una escuela inclusiva que seleccione a su estudiantado o que conduzca sus procesos educativos a la luz de un perfil de egreso único.

Esta vocación de la inclusión por la equidad y el reconocimiento de la diversidad humana trasciende largamente el terreno de lo pedagógico y se presenta habitualmente en el marco de un movimiento de cambio social mucho más amplio, orientado a la construcción de una sociedad más justa (de la Puente, 2009; Escribano y Martínez, 2013; López, 2013; Parrilla, 2002; Thomas y Loxley, 2007; UNESCO, 2004). Es fácil ver aquí, pues, el ideal pluralista de la democracia participativa, tal como lo hemos descrito anteriormente. Pero en la literatura revisionista encontramos además un relato que reconduce esta coincidencia entre inclusión y sociedades pluralistas (en el sentido que aquí damos al término) a un marco ético-axiológico (véase, por ejemplo, véase, por ejemplo, de la Puente, 2009; Escribano y Martínez, 2013; Parrilla, 2002; Thomazet, 2009). De modo que no solo el pluralismo, sino también la ética de la igualdad diferente se hacen parte de la normatividad que guía el proyecto inclusivo.

Lo mismo se puede decir del principio de participación, toda vez que el compromiso político activo al interior de una sociedad depende en buena medida del tipo de educación que reciben sus miembros. Tal como indica Nussbaum (1999), "para ser libres e iguales necesitamos ser ciudadanos de alguna política y, por tanto, necesitamos también ser educados en aquellas destrezas, conocimientos y valores (tanto particulares como universales) que aseguran la plena participación y la igual consideración en nuestra política" (p. 85). De ahí que la pedagogía inclusiva ponga tanto énfasis en lograr la participación efectiva de todo el estudiantado en los centros educativos (Ainscow, 2011; Ainscow y Sandill, 2010; Booth y Ainscow, 2002; Climent, 2009; Echeita 2007; Escribano y Martínez, 2013; Parrilla, 2002; Qvortrup y Qvortrup 2018).

El horizonte normativo de la inclusión coincide, pues, con los tres elementos centrales que distinguen el programa político de la democracia participativa. Esto no significa, de ningún modo, que la educación inclusiva pueda reducirse a un programa político; de hecho, además de esta dimensión política, la inclusión tiene al menos otras dos dimensiones, una pedagógica y otra epistemológica. Lo que hemos querido poner de relieve aquí es que una concepción del proyecto inclusivo que no incorpora en el corazón de dicho proyecto la aspiración de realizar los ideales de la democracia participativa, no representa apropiadamente el concepto de educación inclusiva que caracteriza a las propuestas revisionistas.

6 En parte por esto (pero también por otras razones) creemos que Paulo Freire puede considerarse un precursor de la educación inclusiva (véase, por ejemplo, Freire, 1973). 


\section{Consideraciones finales}

Es frecuente que la educación inclusiva sea representada como un proceso interminable antes que como un estado al cual se llegará algún día (véase, por ejemplo, Ainscow y Miles, 2008; Booth y Ainscow, 2002; Climent, 2009; Escribano y Martínez, 2013). Parte de lo que subyace a esta idea es, creemos, un reconocimiento de que la exclusión es un riesgo permanente y en cierto sentido inevitable (véase, por ejemplo, Hilt, 2015; Qvortrup y Qvortrup, 2018). Por eso es tan importante, a nuestro juicio, conservar el concepto de inclusión, pese a que haya cierta confusión respecto de su uso. Porque la educación, entendida a la luz de ese concepto, "supone una lucha activa contra la exclusión" (Ainscow y Miles, 2008, p. 24); y tener esto presente en todo momento, desde las palabras mismas con que elegimos hablar de la educación, es deseable por al menos dos razones. Primero, porque puede ayudar a mantener en el terreno de lo explícito la motivación política que subyace a la tarea educativa (algo que algunos parecen olvidar de tiempo en tiempo): hablar de inclusión es hablar de una reacción a los procesos de exclusión generados y perpetuados por los ensayos democráticos de la modernidad. Segundo, porque ese fracaso de la democracia moderna fue, en buena medida, resultado de un dispositivo educacional que, para usar la imagen de Slee (2018), tiene la exclusión metida hasta los huesos; de modo que conceptualizar la tarea educativa como un movimiento en la dirección contraria - hacia la inclusión - es al menos un primer paso para cumplir con el deber moral de superar de una vez por todas el proyecto escolar de la modernidad.

\section{Referencias bibliográficas}

Aedo-Richmond, R. (2000). La educación privada en Chile: un estudio bistórico-analítico desde el período colonial hasta 1990. Santiago: Ril Editores.

Agbenyega, J.S. y Klibthong, S. (2014). Assessing Thai early childhood teachers' knowledge of inclusive education. International Journal of Inclusive Education, 18(12), 1247-1261. https://doi.org/10.1080/13603116.2014.886306

Aguerrondo, I. (2008). Revisar el modelo: un desafío para lograr la inclusión. Prospects, 38(1). https://doi.org/10.1007/s11125-008-9059-9

Ainscow, M. (2011). Desarrollo de escuelas inclusivas. Ideas, propuestas y experiencias para mejorar las instituciones escolares. Madrid: Narcea.

Ainscow, M. y Miles, S. (2008). Por una educación para todos que sea inclusiva: ¿Hacia dónde vamos ahora? Perspectivas, 38(1), 17-45. Recuperado de https://bit.ly/2nWHdeC.

Ainscow, M. y Sandill, A. (2010). Developing inclusive education systems: the role of organisational cultures and leadership. International Journal of Inclusive Education, 14(4), 401-416. https://doi.org/10.1080/13603110802504903

Artiles, A., Kozleski, E.B., Dorn, S., y Christensen, C. (2006). Learning in inclusive education research: Re-mediating theory and methods with a transformative agenda. Review of Research in Education, 30(1), 65-108. https://doi.org/10.3102/0091732x030001065

Bailey, L., Nomanbhoy, A. y Tubpun, T. (2015). Inclusive education: teacher perspectives from Malaysia. International Journal of Inclusive Education, 19(5), 547-559. https://doi.org/10.1080/13603116.2014.957739

Bellei, C. (2013). El Estudio de la segregación socioeconómica y académica de la educación Chilena. Estudios pedagógicos, 9(1), 325-345. https://doi.org/10.4067/s0718$\underline{07052013000100019}$

Booth, T. (1998). From "special education" to "inclusion and exclusion in education". En P. Haug y J. Tøssebro (Eds.), Theoretical Perspectives on Special Education. Kristiansand Høyskole Forlaget: Norwegian Academic Press. 
Booth, T. y Ainscow, M. (2002). Index for inclusion: Developing learning and participation in schools. Bristol: Centre for Studies on Inclusive Education.

Bourdieu, P. (2000). Cuestiones de sociología. Madrid: Akal.

Bourdieu, P. y Passeron, J.C. (1981). La reproducción: elementos para una teoría del sistema de enseñanza. Barcelona: Laia.

Canto Sáenz, R. (2016). Participación ciudadana, pluralismo y democracia. Nueva Época, (4), pp. 54-75. https://doi.org/10.32399/rtla.10.41.206

Casanova, M.A. (2011). Educación inclusiva: un modelo de futuro. Madrid: Wolters Kluwer.

Castel, R. (1995). De la exclusión como estado a la vulnerabilidad como proceso. Archipiélago, (21), pp. 27-36. Recuperado de https://bit.ly/2nZG3io.

Chomsky, N. (2000). Chomsky on miseducation. Lanham: Rowman \& Littlefield.

Clark, C., Dyson, A. y Millward, A. (1995). Towards inclusive schools? London: David Fulton.

Climent, G.I. (2009). La educación inclusiva: de la exclusión a la plena participación del alumnado. Barcelona: Horsori.

Cortina, A. (1993). Ética aplicada y democracia radical. Madrid: Editorial Tecnos.

De Boer, A., Pijl, S.J. y Minnaert, A. (2011). Regular primary schoolteachers' attitudes towards inclusive education: a review of the literatura. International Journal of Inclusive Education, 15(3), 331-353. https://doi.org/10.1080/13603110903030089

de la Puente, J.L. (2009). Hacia una educación inclusiva para todos. Revista complutense de educación, 20(1), 13-31. Recuperado de https://bit.ly/2HNT7ip.

Dewey, J. (2012). Democracy and Education. San Bernardino, CA: Simon \& Brown.

Díaz Arce, T. y Druker, S. (2007). La democratización del espacio escolar: una construcción en y para la diversidad. Estudios pedagógicos, 33(1), 63-77. https://doi.org/10.4067/s0718-07052007000100004

Dubet, F. (2003). Mutaciones cruzadas: la ciudadanía y la escuela. En J. Benedicto y M.L. Morán (Coords.), Aprendiendo a ser ciudadanos. Experiencias sociales y construcción de la ciudadanía entre los jóvenes. Madrid: Injuve.

Dubet, F. (2004). Conflictos de normas y ocaso de la institución. Estudios Sociológicos, 22(64), 3-24. Recuperado de https://bit.ly/2nUBENQ

Durkheim, É. (1977). La Educación Moral. Buenos Aires: Editorial Losada.

Dworkin, R. (2000). ¿Entran en conflicto la libertad y la igualdad? En P. Barker (comp.), Vivir como iguales. Barcelona: Paidós.

Echeita, G. (2007). Educación para la inclusión o educación sin exclusiones. Madrid: Narcea.

Escribano, A. y Martínez, A. (2013). Inclusión educativa y profesorado inclusivo: aprender juntos para aprender a vivir juntos. Madrid: Narcea.

Escudero, J.M., y Martínez, B. (2011). Educación inclusiva y cambio escolar. Revista iberoamericana de educación, 55, 85-105. https://doi.org/10.35362/rie550526

Florian, L. (2008). Special or inclusive education: future trends. British Journal of Special Education, 35(4), 202-208. https://doi.org/10.1111/j.1467-8578.2008.00402.x

Fraser, N. (1996). Justice Interruptus: Rethinking Key Concepts of a 'Postsocialist' Age. New York: Routledge.

Fraser, N. (2000). ¿De la redistribución al reconocimiento? Dilemas de la justicia en la era postsocialista. New left review, 1, 126-155. Recuperado de https://bit.ly/2o1swH3

Fraser, N. (2008). Rethinking Recognition: Overcoming Displacement and Reification in Cultural Politics. En N. Fraser y K. Olson (Eds.), Adding Insult to Injury: N. Fraser Debates her Critics (pp. 129-141). London: Verso. 
Fraser, N. (2009). La justicia social en la era de la política de identidad: redistribución, reconocimiento y participación. Revista de Trabajo, 4(6). Recuperado de https://bit.ly/2oG6WIB

Freire, P. (1973). Pedagogía del oprimido. Buenos Aires, Argentina: Siglo Veintiuno.

Gaete, A., y Ayala, C. (2015). Enseñanza básica en Chile: las escuelas que queremos. Calidad en la educación, (42), 17-59. https://doi.org/10.4067/s0718-45652015000100002

Gaete, A., y Gómez, V. (2019). Education and Poverty. Cambridge: Cambridge Scholars.

Gaete, A., y Ayala, C. (2015). Enseñanza básica en Chile: las escuelas que queremos. Calidad en la educación, (42), 17-59. https://doi.org/10.4067/s0718-45652015000100002

García-Huidobro, J.E. (2001). Conflictos y alianzas en las reformas educativas: siete tesis basadas en la experiencia chilena. En S. Martinic y M. Pardo (Eds.), Economía Política de las Reformas Educativas en América Latina (pp. 205-2018). Santiago: PREL/CIDE.

Gerschel, L. (2003). Igualdad de oportunidades y necesidades educativas especiales: equidad e inclusión, En C. Tilstone, L. Florian y R. Rose (Eds.), Promoción y desarrollo de prácticas educativas inclusivas (pp. 101-122). Madrid: EOS.

Giddens, A. (1987). La constitution de la société. Paris : Presses Universitaires de France.

Gimeno Sacristán, J. (2001). Educar y convivir en una cultura global. Las exigencias de la ciudadanía. Madrid: Morata.

Giroux, H. (1986). Teorías de la reproducción y la resistencia en la nueva sociología de la educación: un análisis crítico. Revista Colombiana de Educación, (17). https://doi.org/10.17227/01203916.5140

Göransson, K. y Nilholm, C. (2014). Conceptual diversities and empirical shortcomings - a critical analysis of research on inclusive education. European Journal of Special Needs Education, 29(3), 265-280. https://doi.org/10.1080/08856257.2014.933545

Graham, L. J., y Slee, R. (2008). An illusory interiority: Interrogating the discourse/s of inclusion. Educational Philosophy and Theory, 40(2), 277-293. https://doi.org/10.1111/j.1469-5812.2007.00331.x

Grignon, C. (1990). Cultura dominante, cultura escolar y multiculturalismo popular. Educación y Sociedad, 12.

Hilt, L.T. (2015). Included as Excluded and Excluded as Included: Minority Language Pupils in Norwegian Inclusion Policy. International Journal of Inclusive Education, 19(2), 165-182. https://doi.org/10.1080/13603116.2014.908966

Hodkinson, A. (2005). Conceptions and misconceptions of inclusive education: A critical examination of final-year teacher trainees' knowledge and understanding of inclusion. Research in Education, 73(1), 15-28. https://doi.org/10.7227/rie.73.2

Hopenhayn, M. (2006). La educación en la actual inflexión epocal: Una perspectiva latinoamericana. Revista PRELAC, 2, 12-25. Recuperado de https://bit.ly/2mlPw3a

Infante, M. (2010). Desafíos a la formación docente: inclusión educativa. Estudios Pedagógicos, 36(1), 287-297. https://doi.org/10.4067/s0718-07052010000100016

Kingston, P.W. (1986). Resistance theory: How Marxists interpret student life. Sociological Forum, 1(4), 717-725. https://doi.org/10.1007/bf01107345

Kymlicka, W. (1995) Multicultural citizenship: A liberal theory of minority rights. New York: Oxford University Press.

León, M.J. (2012). Educación inclusiva. Evaluación e intervención didáctica para la diversidad. Madrid: Síntesis. 
Lipsky, D.K. y Gartner, A. (1996). Inclusion, school restructuring, and the remaking of American society. Harvard Educational Review, 66, pp. 762-796. https://doi.org/10.17763/haer.66.4.3686k7x734246430

López, M. (2013). La educación inclusiva, una nueva cultura. En S. López de Maturana (Ed.), Inclusión en la vida y la escuela (pp. 262-284). La Serena: Editorial Universidad de La Serena.

Luna, L. y Gaete, A. (2019). Diversity and the Failure of the Civilizing Project, En C. Matus (Ed.), Ethnography and Education Policy-A Critical Analysis of Normalcy and Difference in Schools (pp. 11-134). Singapore: Springer Book.

Merton, R. (1964). Teoría y estructuras sociales. México: F. C. Económica.

Mistral, G. (2017). Pasión de enseñar (pensamiento pedagógico). Valparaíso: Editorial UV de la Universidad de Valparaíso.

Nilholm, C. (2006). Special education, inclusion and democracy. European Journal of Special Needs Education, 21(4), 431-445. https://doi.org/10.1080/08856250600957905

Nussbaum, M. (ed.) (1999). Los límites del patriotismo. Identidad, pertenenciay "ciudadanía mundial". Barcelona: Paidós.

Parekh, B. (1995). Cultural Pluralism and the Limits of Diversity. SAGE Journals, 20(4), 431457. https://doi.org/10.1177/030437549502000402

Parekh, B. (2001). The future of multi-ethnic Britain: reporting on a report. The Round Table: The Commonwealth Journal of International Affairs, 90(362), 691-700. https://doi.org/10.1080/00358530120087422

Parrilla, Á. (2002). Acerca del origen y sentido de la educación inclusiva. Revista de educación, 327, pp. 11-29. Recuperado de https://bit.ly/2nTLjV1

Pedraza, A. (2015). ¿La democracia participativa: utopía o realidad? Cuadernos de Ciencias Jurídicas y Politica Internacional, 8(1), 71-101.https://doi.org/10.21500/20115733.2581

Peña, C. (2015) Escuela y Vida Cívica, En C. Cox y J.C. Castillo (Eds.), Aprendizaje de la ciudadanía: contextos, experiencias y resultados. Santiago: Ediciones Universidad Católica de Chile.

Qvortrup, A. y Qvortrup, L. (2018). Inclusion: Dimensions of inclusion in education. International Journal of Inclusive Education, 22(7), 803-817. https://doi.org/10.1080/13603116.2017.1412506

Rafferty, Y., Boettcher. C. y Griffin, K.W. (2001). Benefits and risks of reverse inclusion for preschoolers with and without disabilities: Parents' perspectives. Journal of Early Intervention, 24, 266-86. https://doi.org/10.1177/105381510102400403

Rosas, R. y Santa Cruz, C. (2013). Dime en qué colegio estudiaste y te diré qué CI tienes. Radiografía al desigual acceso al capital cognitivo en Chile. Santiago de Chile: Ediciones UC.

Ruijs, N.M., y Peetsma, T.T.D. (2009). Effects of inclusion on students with and without special educational needs reviewed. Educational Research Review, 4(2), 67-79. https://doi.org/10.1016/j.edurev.2009.02.002

Ruiz, C. (2012). Notas sobre Valentín Letelier y la fundación del Instituto Pedagógico. Anales de la Universidad de Chile, (4), 99-101. https://doi.org/10.5354/0717-8883.2012.25270

Sánchez-Parga, J. (2005). El Oficio de Antropólogo. Crítica de la Razón (Inter) Cultural. Quito: Centro Andino de Educación Popular.

Santos, B.S. (2002). Democratizar a democracia: os caminhos da democracia participativa. Rio de Janeiro: Civilização Brasileira.

Schumpeter, J. (1942). Capitalism, Socialism and Democracy. New York; London, Harper \& Brothers. 
Serrano, S., Ponce de León, M. y Rengifo, F. (2012). Historia de la educación en Chile (18102010): Aprender a leer y escribir (1810-1880). Santiago: Taurus.

Skliar, C. y Téllez, M. (2008). Conmover la educación. Ensayos para una pedagogía de la diferencia. Buenos Aires: Noveduc.

Slee, R. (2001). 'Inclusion in Practice': does practice make perfect? Educational Review, 53(2), 113-123. https://doi.org/10.1080/00131910120055543

Slee, R. (2018). Inclusive education isn't dead, it just smells funny. New York, NY: Routledge.

Spindler, G.D. (1987). The transmission of culture, En G.D. Spindler (Ed.), Education and cultural process. Anthropological approaches (pp. 303-334). Heights, Illinois: Waveland Press.

Stainback, S. y Stainback, W. (1999). Aulas inclusivas. Un nuevo modo de enfocar y vivir el currículo. Madrid: Narcea.

Subirats, J. (2005). Democracia, participación y transformación social. Polis, 12.

Taylor, C. (1997). The politics of recognition. New contexts of Canadian criticism, 98, pp. 25-73.

Taylor, C. (2012). Democracia republicana/Republican Democracy. Santiago, Chile: LOM Ediciones.

Tedesco, J.C. (2000). Educar en la sociedad del conocimiento. Argentina: Fondo de Cultura Económica.

Tedesco, J.C. (2002). Educación y ciudadanía paritaria. En F. Imbernón (Coord.), Cinco ciudadanias para una nueva educación (pp. 47-62). España. Editorial GRAÓ.

Terrén, E. (2003). Educación democrática y ciudadanía multicultural: el reaprendizaje de la convivencia. En J. Benedicto y M.L. Morán (Coords.), Aprendiendo a ser ciudadanos. Experiencias sociales y construcción de la ciudadanía entre los jóvenes (pp. 259-279). Madrid: Injuve.

Thomas, G. y Loxley, A. (2007). Deconstructing Special Education and Constructing Inclusion. Berkshire: McGraw-Hill.

Thomazet, S. (2009). From Integration to Inclusive Education: Does Changing the Terms Improve Practice? International Journal of Inclusive Education, 13(6), 553-563. https://doi.org/10.1080/13603110801923476

Tiramonti, G. (2005). La escuela en la encrucijada del cambio epocal. Educação \& sociedade, 26(92). https:// doi.org/10.1590/s0101-73302005000300009

Todorov, T. (2001). La Conquista del América. El problema del otro. Argentina: Siglo XXI.

Touraine, A. (1997). ¿Podremos vivir juntos? Iguales y diferentes. Argentina: Fondo de Cultura Económica.

Touraine, A. (2000) Igualdad y diversidad. Las nuevas tareas de la democracia. México: Fondo de Cultura Económica.

Turnbull, A.P., Turnbull, R., Shank, M. y Leal, D. (1995). Exceptional lives: Special education in today's schools. Upper Saddle River, NJ: Merrill/Prentice Hall.

UNESCO (2004). Temario abierto sobre educación inclusiva. Chile: UNESCO.

Walzer, M. (2008). Spheres of justice: A defence of pluralism and equality. EE.UU.: Basic books.

Woodcock, S. y Hardy, I. (2017). Beyond the binary: rethinking teachers' understandings of and engagement with inclusion. International Journal of Inclusive Education, 21(6), 667-686. https://doi.org/10.1080/13603116.2016.1251501

Zapata-Barrero, R. (2001). Ciudadanía, democracia y pluralismo cultural: hacia un nuevo contrato social. España: Anthropos Editorial.

Zaragoza, F.M. (2002). Ciudadanía democrática. Reinventar la democracia, la cultura de paz, la formación cívica y el pluralismo. En F. Imbernón (Coord.), Cinco ciudadanías para una nueva educación. España: Editorial GRAÓ. 


\section{Para citar este artículo}

Gaete, A., \& Luna, L. (2019). Educación inclusiva y democracia. Revista Fuentes, 21(2), 161-175. [Fecha de consulta: dd/mm/aa]. doi: 10.12795/revistafuentes.2019.v21.i2.02. 